\title{
运用过程性评价进行高校英语专业《英语国家社会与文化》 课程考核改革
}

\section{Using Process Evaluation to Carry out College English Major Social and Cultural Mosaics of English Speaking Countries Curriculum Assessment reform}

\author{
卢玉娜 \\ Yuna Lu \\ 兴义民族师范学院 中国·贵州兴义 562400 \\ Xingyi Normal University for Nationalities, Xingyi, Guizhou, 562400, China
}

\begin{abstract}
摘 要: 新课程改革提出了对各学科进行过程性评价的考核方法。针对兴义民族师范学校 2019 年英语专业和翻译专业本 科所开设的《英语国家社会与文化》这门专业必修课，笔者试图用过程性评价的考核方式，实现高校英语专业高年级教学 质量的有效提高, 培养学生自主学习能力及学习的自觉性。论文主要剖析在《英语国家社会与文化》课程中所运用的教学 方式和方法，以及通过这样的方式方法如何对本课程进行过程性评价，最后达到预期目的。
\end{abstract}

\begin{abstract}
The new curriculum reform puts forward the assessment method of process evaluation for each subject. Aiming at the compulsory course Social and Cultural Mosaics of English Speaking Countries offered by Xingyi Normal University for Undergraduates majoring in English and translation in 2019, the author tries to effectively improve the teaching quality of senior English majors in colleges and universities by means of process evaluation, so as to cultivate students' independent learning ability and consciousness of learning. This paper mainly analyzes the teaching methods and methods used in the Social and Cultural Mosaics of English Speaking Countries, and passed How to evaluate the course in this way and finally achieve the expected goal.
\end{abstract}

关键词: 过程性评价; 英语; 《英语国家社会与文化》; 考核改革

Keywords: process evaluation; English; Social and Cultural Mosaics of English Speaking Countries; assessment reform

基金项目：项目编号：课程考 2020 年课程考核方式改革立项第 51 《英语国家社会与文化》核方式改革的研究与探索。

DOI: $10.36012 /$ sde.v2i12.2602

\section{1 引言}

《英语国家社会与文化》是英语专业和翻译专业本科的 一门专业必修课。此课程以英语为媒介, 比较系统地向学生 阐述主要英语国家的社会与文化背景, 如地理、历史、政治、 经济、社会生活和文化传统等方面的基本知识 ${ }^{[1]}$ 。它是英语 和翻译专业学生在高年级阶段学习文学和翻译等课程的基 础。本课程以认识和解读英语国家文化为切入点, 启发学生 在大学阶段的学习自主性、分析思考的能动性和基于知识积 累基础上的创造性, 帮助学生深化语言学习与文化学习的内
涵关联, 提升学习语言的实效和在真实世界中的应用能力。 该课程的教学在提高学生跨文化意识的基础上, 不但可以提 高学生的文化观察能力、文化思索能力、文化甄别能力和文 化探索能力, 而且还可以提高学生在跨文化语言运用过程中 对文化差异的敏感性、宽容性和处理文化差异的灵活性，从 而改善学生跨文化语言运用能力。

传统的考核方式常用书面闭卷考试，其中，期末卷面 分数占课程总成绩的 $70 \%$, 平时成绩占 $30 \%$ 。而文化课程 期末考试的内容主要来源于课堂讲授过的理论知识, 并充分

【作者简介】作者简介 : 卢玉娜（1979 ), 女, 壮族，贵州兴义人，教授，从事英美文学与中美跨文化传播研究。 
考虑教学大纲的重难点, 一般掌握, 重点掌握等的要求, 试 卷题型由选择题, 填空题, 判断题, 名词解释, 简答题和综 合论述题等构成。传统考核评价不足之处在于 : 教师多考虑 是否完成教学计划和学生是否能通过期末考试; 学生把在期 末考试中获得较好分数作为课程学习的唯一目标, 他们通常 采取临时突击的方式死记硬背, 通过考试, 并不在意是否确 实掌握了相关知识, 并用这些知识去解决和分析相关问题 ; 这种终结性考试以理论考核为主导, 不利于文化课程中所应 体现的应用能力的培养, 不利于培养学生自主学习习惯和自 主学习能力, 不利于培养学生分析问题和解决问题的能力 ${ }^{[2]}$ 。 根据《英语国家社会与文化》的课程特点，故现对本课程提 出考试改革。

\section{2 过程性评价的内涵}

教学评价是课程教学的目的, 针对任何课程期终的教 学评价都是教学的终点。教学改革在近些年来越来越被重 视, 一线老师们开始思考终结性评价目的和意义及所能到达 的教书育人的终极目标 ${ }^{[3]}$ 。因此教学改革不断发展并深人, 课程评价理念从终极目标取向过渡到过程取向，评价方式从 结果性评价过渡到过程性评价。过程性评价是 20 世纪 80 年 代以来形成的一种评价范式, 是一种在课程实施过程中对学 生学习进行评价的方式, 该评价方式重视引导学生解决实际 问题, 针对学生自身发展前后, 学生个体有相关性的不同侧 面进行的比较, 属于课堂学习评价, 是一种发展性的评价方 式。过程性评价强调学生的学习动机, 过程和效果, 三位一 体的评价, 全面、灵活、深入地进行过程性强调和注重。

过程性评价是学生通过评价学会评价, 渗透叙事整体 评价自己的 “动机态度、过程、效果” 三维过程 ${ }^{[4]}$ 。其 “过 程” 相对于 “结果”, 不是只关注过程而不关注结果的评价, 也不是单纯地观察学生的表现，而是计划把握整个过程，整 体评价整个过程。自我评价、学生评价、学生互评贯穿于过 程性评价方式中。挖掘教学过程的 “所以然” 与 “之所以然”, 不脱离于教学活动而独立存在, 参与教学价值的建构和生成, 从而达到课程教学的目标, 引导学生学习和优化教师教学。

\section{3 过程性评价在文化课程中的实施}

英语专业文化课程在英语专业中是一门较特殊的课程, 开设的主要目的是让学习英语专业的学生对英语国家的地
理、经济、历史、政治、教育、文化等有一定了解，以此加 强学生的专业化水平 ${ }^{[5]}$ 。传统的评价方式只注重学生对知识 的掌握, 强调期终结果的评价。就专业课程特色而言, 文化 课程考核方式的改革迫在眉睫。过程性评价的出现缓解了英 语专业文化课程考核方式的窘境，从教师满堂灌到学生自律 学习的培养, 从被动学习到学生自觉思考的培养, 强调学习 过程, 整个教学过程由多个环节组成, 各个环节密不可分, 形成整体。通过过程学习的过渡性、阶段性去发现问题，总 结经验, 矫正错误完善整个过程, 每一个阶段都为下一个阶 段作铺垫，提供帮助、辅与指导，如表 1 、表 2 所示。

\section{表 1 采用考核方法及理由}

\begin{tabular}{c|l}
\hline \multirow{2}{*}{ 课堂表现 } & $\begin{array}{l}\text { 学生课堂教学中抢答并回答问题情况; 课堂教学中 } \\
\text { 回复主题讨论题目的情况; 课堂中的小测情况 }\end{array}$ \\
\hline 作业 & 个人及小组作业结合 \\
\hline 出勤 & 每次课程学习通上的签到情况 \\
\hline 线上学习 & 任务点是否完成 \\
\hline 期末考查 & $\begin{array}{l}\text { 在批改网上撰写一份小论文 }+ \text { 口试回答所提供的问 } \\
\text { 题 (学生通过自己录音保存语音回答的方式进行 ) }\end{array}$ \\
\hline
\end{tabular}

表 2 成绩核算

\begin{tabular}{c|c}
\hline \multirow{4}{*}{ 形成性评价占 $60 \%$} & 小组活动 $10 \%$ ( 课堂小论文) \\
\cline { 2 - 2 } & 平时作业 $30 \%$ \\
\cline { 2 - 2 } & 课堂表现 $10 \%$ \\
\hline \multirow{2}{*}{ 终结性评价占 $40 \%$ (期末考查) } & \\
\cline { 2 - 2 } & 口试 $20 \%$ \\
\hline
\end{tabular}

\section{1 课前准备及小组讨论}

教师提前在课前发布每次课的教学目标及任务和重难 点, 并提前发布课前预习题, 让学生围绕着所给的问答题进 行课前预习。每次发布的课前预习题最少 5 个, 最多 10 个。 用不同的方式进行检查：课中采取自由回答并计分的方式， 同时回答的同学接受全班任何一个同学的提问, 对能针对问 题提出问题的同学给予加分。这种评价方式培养了学生自主 思考的能力和对学习的主动性 ; 课前预习题作为任务安排到 每个小组 (每个班按人数至多分为 8 个小组), 每个小组分 
配一到两个问题, 针对所给的问题, 小组内进行课前讨论, 最后派一位或两位代表在课堂中进行最多五分钟的全英文 呈现, 并加分。主要评价学生对学习的主动性和参与度, 培 养学生从他律到自律 ; 每次课前的预习题, 学生都要按小组 进行课前的自主讨论, 针对问题, 回答问题, 提出问题及质 疑, 组内进行讨论和网络查找资料。由学习委员制定相关表 格对各小组的课前预习情况进行检查和记录, 每个月汇报给 老师。通过这种方式敦促学生进行自主学习; 针对小组学习 的情况, 在学期结束时, 在小组内进行自我评定, 互评和他 评。通过这种评价方式加强学生学习的主动性和自主学习能 力的培养及团队参与度。以上的过程评价方式不但评价了学 生的成绩, 同时培养学生在学习上的各种能力, 也让学生有 的放矢的去学习英语专业知识, 习得文化课程中的知识点。

\section{2 课堂出勤及表现}

每次课前进行学习通签到, 详细记录学生上课迟到, 早 退、旷课等情况, 主要评价学生的学习态度。学生的课堂表 现主要涉及到课堂教学中抢答并回答问题情况; 课堂教学中 回复主题讨论题目的情况; 课堂中的小测情况。通过这样的 方式评价学生在课堂中的参与度, 尤其是对于课堂中的抢答 部分。教师通过学习通发布抢答, 抢到的同学尘须在学习通 群聊里发语音回答, 则加五分。通过这样的方式, 不但评价 了学生在课堂中的参与度, 同时考察学生英语表达能力, 也 锻炼了学生说英语的能力和胆量。通过线上线下的学习方式 相结合, 互补长短, 学生能从不同教学方式中获取知识, 让 学生不枯燥于一种教学方式。

\section{3 课程论文考核}

课程论文以英语国家文化内容为主题, 主要考察学生 英语专业写作能力、知识储备能力、文化知识背景存储能力。 教师根据每个国家的文化背景重难点知识和内容, 拟定作文 题目, 在批改网上发布课堂小论文, 要求学生在规定时间内 自主完成。这样的评价过程主要培养学生英语基本功及提高 学生英语写作能力和知识储备能力。

通过改革此课程的考核形式, 强调过程性评价, 在课 前发布教学目标、重点及难点、预习具体要求, 要求学生在
课前完成自主预习, 并完成预习成效检测, 进入课堂后针对 课前预习的题目进行课堂讨论答疑, 以此达到对学生从 “他 律” 到 “自律” 的培养; 课中针对上课的内容设置课堂小组 讨论, 给 10 分钟, 每组分别派出一位代表来回答讨论的结 果, 每组不能固定一名同学作代表, 使每个同学都有锻炼 的机会 ; 课堂中针对所学内容进行问答题抢答 (用学习通), 抢到的同学以语音或者文字的形式在学习通上回答, 作为课 堂表现之一加分; 口试主要针对外语学科特点, 以培养学生 的口语能力为目的, 同时培养学生分析问题和解决问题的能 力, 作为考试改革中的口试一项占总分的 $20 \%$, 平时课堂 表现优秀者可以免考口试。期末针对课堂教学大纲中提出的 整本书的教学重点, 有目的地让学生进行全英文小论文的撰 写, 通过批改网进行初评, 任课教师进行复评, 作为本课程 考核内容的学组成部分, 占总分的 $20 \%$ 。通过过程性评价 和总结性评价, 双管齐下, 培养学生自主学习意识的和达到 对本课程知识融会贯通的目的。

\section{4 结语}

课程考核方式改革注重学习过程, 通过过程式学习评 价学生, 有助于客观地评价学生的学习行为, 督促学生全面 发展, 培养学生正确的学习习惯, 提高学生自主学习能力、 口头表达能力、英语撰写能力、逻辑思维能力等全方面发展。

\section{参考文献}

[1] 王恩铭. 英语国家概况 (修订版) [M]. 上海: 上海外语教育出 版社, 2013.

[2] 曾庆日,刘卫平. 过程性评价让学生从“他律” 走向 “自律” 厦门六中文明习惯养成教育探索 [J]. 福建基础教育研究, 2016 (2) :20-22.

[3] 李郭芝. 过程性评价在高中英语教学中的运用 [J]. 生物技术世 界,2013（6）:133.

[4] 郑明达. 实施过程性评价的关键之一 [J]. 中小学信息技术教 育 $, 2010(1): 27-28$

[5] 赵振军, 胡贤春, 张霞. 过程性评价在《茶叶机械学》课程考 核方法改革中的探索与实践 [J]. 福建茶叶, 2020 (4):43. 